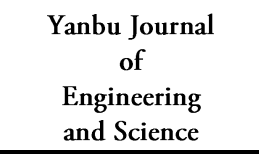

ISSN: 1658-5321
Vol. 2, April $2011(1432 \mathrm{H})$

www.yic.edu.sa/yjes

\title{
MODELING AND NEURAL CONTROL OF QUADROTOR HELICOPTER
}

\author{
M Yasir Amir ${ }^{1}$ and Vali uddin Abbas ${ }^{2}$ \\ ${ }^{1}$ Department of Telecommunication Engineering, National University of Computer and Emerging Sciences (NUCES), \\ Karachi, Pakistan, Email: y_asir81@yahoo.co.uk \\ ${ }^{2}$ Department of Electronic and Power Engineering, National University of Sciences and Technology (PNEC) \\ Karachi, Pakistan
}

\section{ABSTRACT}

Quadrotor Helicopter or simply quadrotor is rotorcraft that has four lift-generating propellers. Two of the propellers spin clock wise and the other two counter-clockwise. Control of the machine can be achieved by varying relative speed of the propellers. Quadrotor concept is not new, however the modern quadrotors are mostly unmanned. Advancement in miniaturized IMU technology, availability of high speed brushless motors and high power to weight ratio Li-Polymer battery technology, quadrotors can now be successfully designed and fabricated.

This paper proposes a mathematical model of quadrotor dynamics and a control scheme based on Direct Inverse Neural Control. In modeling A simplified approach is adopted where the gyroscopic effect and air friction on frame of machine has been neglected, resulting in a simplified model, which is useful for designing a controller to stabilize the plant in hover state. Proposed model is non-linear since the rotor dynamics are a function of square of motor inputs.

The neural network based controller, exploits the multiple layer perceptron trained by the back propagation algorithm. Direct inverse control scheme uses the idea of canceling out the dynamics of a plant by training the controller to approximate the inverse of the plant. This scheme however requires the plant to have a stable inverse.

\section{KeYwords: Quadrotor, Dynamics, Propeller, Moment of inertia, Thrust, Roll, Pitch, Direct Inverse Control, Neural networks, Multiuplelayer perceptron, Backpropagation}

\section{INTRODUCTION}

A Quadrotor Helicopter, or simply Quadrotor, is a helicopter with four propellers mounted on motors. Two of the motors generate lifting thrust by spinning their propellers clockwise and other two counterclockwise. Control of the machine can be achieved by varying the relative speed of the propellers. Quadrotor concept is not very new. In 1922, Georges de Bothezat contructed a truss structure of intersecting beams, where the propeller was located at each end of the $\mathrm{x}$-shaped structure [1].

The modern quadrotors are mostly unmanned. Due to the availability of highspeed brush-less motor, inertial measurement units based on MEMS technology and high power and energy to weight ratio $(>150 \mathrm{~W} / \mathrm{kg})$ Li-polymer batteries, unmanned quadrotors can now be designed and fabricated [2] but their control is still a great challenge.

In the past few years quadrotor have mustered 
quite a lot of research. Mesicopter [3] was an ambitious project, which explored the ways to fabricate small (centimeter) sized vehicles. Such vehicles can be used for gathering meteorological and planetary atmospheric data. The OS4 project [4] started in March 2003, aimed at developing devices for searching and monitoring hostile indoor environments. The X4 Flyer project of Australian National University [5], aimed at developing a quadrotor for outdoor and indoor applications. The control system of this vehicle is based on classical control methodology.

\section{ASSUMPTIONS}

A quadrotor simply consists of four dc motors on which propellers are mounted. These motors are arranged at the corners of a + shaped frame, where all the arms make an angle of 90 degrees with one another. As shown in Figure 1, two of the rotors or propellers spin in one direction and the other in the opposite direction. The motors labeled as $M_{1}$ and $M_{3}$ spin in the clockwise direction with velocity and other two in the opposite direction. Each spinning propeller generates vertically upward lifting force. All the motion of machine is a consequence of this force.

The mathematical model developed in this paper is based on certain basic assumptions as given below:

- Quadrotor body is rigid.

- Propellers are rigid.

- There is no air friction on quadrotor body.

- Free stream air velocity is zero.

- Drag torque $\tau \mathrm{d}$ is proportional to propeller speed with $\mathrm{D}$ as drag constant.

- Design is symmetrical.

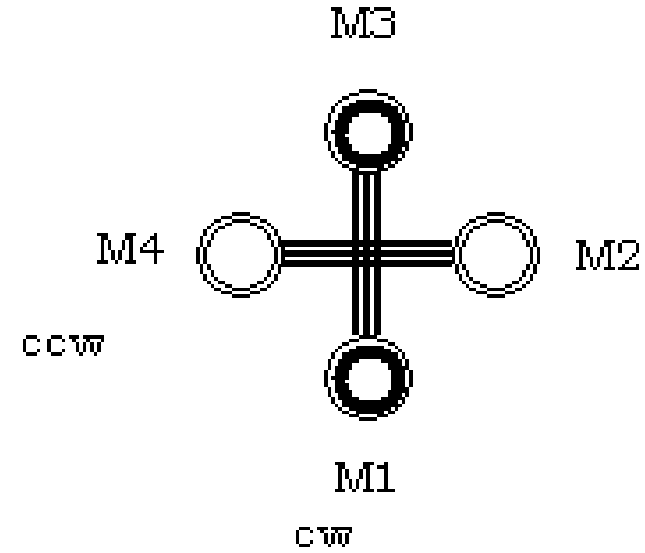

Fig.1. Top vew of quadrotor

\section{SELECTION OF FRAME OF REFERENCE}

In order to model quadrotor dynamics a frame of reference should be defined. Let $\mathrm{E}$ be an earth fixed frame with mutually orthogonal axes $x, y, z$ with unit vector and $i, j$ and $k$. The center point of this frame is O. Quadrotor is placed in this frame of reference with its center of mass at $\mathrm{O}$. If $l$ is the length of arms then each motor $M_{1}$ to $M_{4}$ can be located by position vectors as shown in Figure 2, and given as:

$$
\begin{aligned}
& \vec{L}_{1}=l \hat{i} \\
& \vec{L}_{2}=l \hat{j} \\
& \vec{L}_{3}=-l \hat{i} \\
& \vec{L}_{4}=-l \hat{j}
\end{aligned}
$$

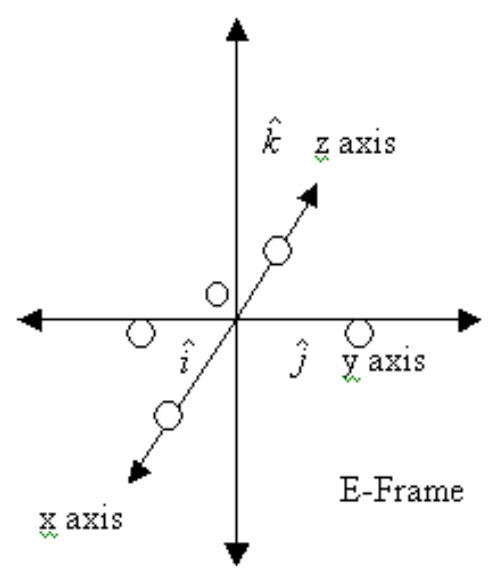

Fig.2. Frame of Reference. (Circles are showing motor positions.) 


\section{YAW, ROLL AND PITCH ANGLE}

The free body diagrams of quadrotor with reference to $E$ are shown in Figure 3. Figure 3(a) shows the yaw angular displacement which is represented by $\psi$, and it is due to rotation about positive $z$-axis.
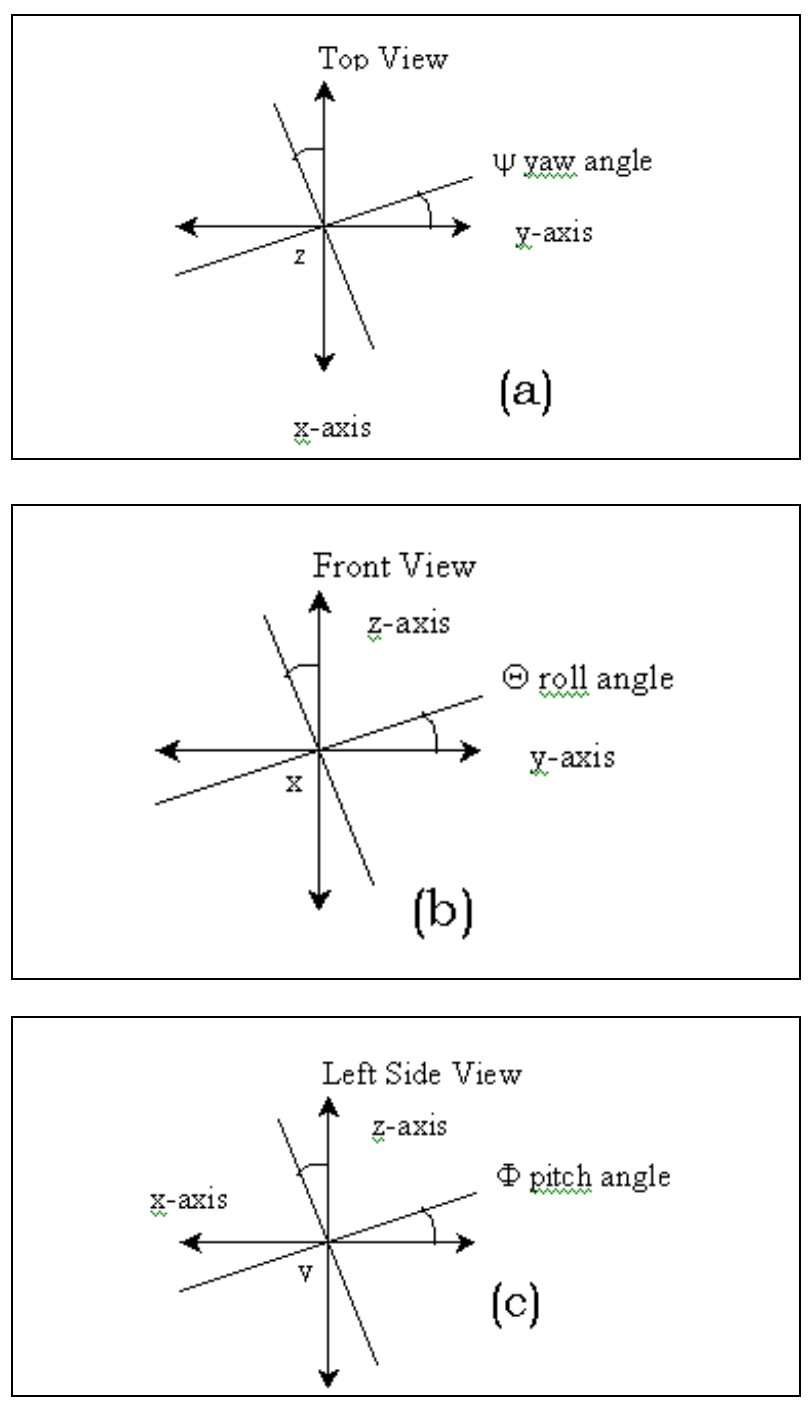

Fig.3. Roll, pitch and yaw angles.

Figure 3(b) shows the front view of quadrotor along with an axis that is perpendicular to the plane formed by the frame of machine. This angular displacement is due to the rotation about positive $x$-axis, and is represented by $\Theta$. Figure 3(c) represents the pitch angular displacement, which is about positive $y$-axis and is represented by $\Phi$.

\section{FORCES ACTING ON QUADROTOR}

Lifting forces generated by the spinning propeller and the weight, are responsible for all the motion of body, as the external effects such as air friction, wind pressure etc. have been neglected. Consider a detailed free body diagram of quadrotor with reference to $\mathrm{E}$, as shown in Figure 4.

All the forces shown in the figure by $F_{i}$ are located from the origin of $E$ by position vectors $\vec{L}_{i}$ as mention in the previous section. The design of quadrotor motors and propellers is assumed to be such that these thrust forces always act perpendicular to the plane of propellers and therefore plane of quadrotor body.

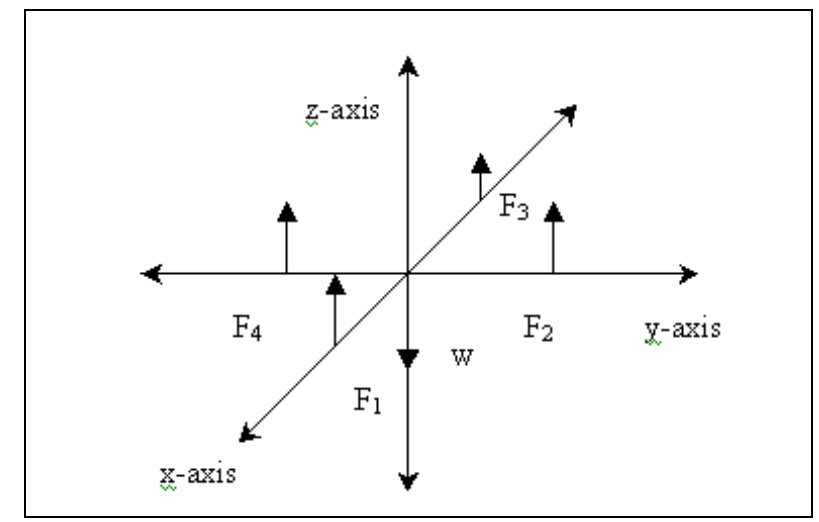

Fig.4. Detailed free body diagram of quadrotor.

The center of mass of machine is located at the origin of the $E$-frame. And the weight force acts at this point. Weight force is always along negative z-axis. Propellers mounted on motors $M_{1}$ and $M_{3}$ spin in the clockwise direction at speeds $\Omega_{1}$ and $\Omega_{3}$ respectively and those mounted on motors $M_{2}$ and $M_{4}$ spin in counter-clockwise direction at speeds $\Omega_{2}$ and $\Omega_{3}$ respectively.

The imbalance of the forces $F_{i}$, where $\mathrm{i}=1,3$ or 2, 4 results in moment, along a direction perpendicular to the plane formed by the force $F_{i}$ and the vector $\vec{L}_{i}$. This torque is 
responsible for the rotation of machine along $\mathrm{x}$-axis and $\mathrm{y}$-axis. The rotation about $\mathrm{z}$-axis is due to imbalance of clockwise and counterclockwise torques.

\section{MOMENTS OF INERTIA OF QUADROTOR BODY}

Determination of moment of inertia can be divided into two parts, firstly about $x$ and $y$ axis and secondly about $z$-axis. It is assumed that if the machine is rolling, pitching and spinning etc. then that does not change the moment of inertia about a specific axis.

\subsection{MOMENTS OF INERTIA ALONG X AND Y-AXIS}

In derivation of moment of inertia along $x$ (and $y$ ) axis following assumptions are made:

- Motors $M_{1}$ and $M_{3}$ are cylindrical in shape with radius $\rho$, height $h$ and mass $m$.

- Central hub or body of quadrotor is also cylindrical with radius $R$, height $H$ and mass $m_{0}$.

Since moment of inertia about $x$-axis is to be determined, therefore consider only the rolling motion. The moment of inertia about $x$-axis consists of two parts:

- Due to motion of motors $M_{2}$ and $M_{4}$ about $x$-axis with radius of rotation $l$.

- Due to $M_{1}, M_{3}$ and central hub about $\mathrm{x}$-axis.

The moment of inertia of a cylinder about an axis perpendicular to its body, as specified in [6], is

$$
I=\frac{\text { mass }(\text { radius })^{2}}{4}+\frac{\text { mass }(\text { height })^{2}}{12}
$$

The moment of inertia of two identical spheres connected together by a horizontal arm, and rotating about a vertical axis, which is passing through the center of the arm and is perpendicular to it, as specified in [6], is: $I=0.5 \times$ mass $\times(\text { armlength })^{2}$
For part(a) the moment of inertia due to motors $M_{2}$ and $M_{4}$ rotating about x-axis is approximated by:

inertia $=2 m l^{2}$

For part(b) the moment of inertia due to $M_{1}$, $M_{3}$ and central hub about x-axis is approximated by:

inertia $=2\left[\frac{m l^{2}}{4}+\frac{m h^{2}}{12}\right]+\frac{m_{o} R^{2}}{4}+\frac{m_{o} H^{2}}{12}$

Therefore the total inertia due to part (a) and part (b) is:

$I_{x x}=\frac{m \rho^{2}}{2}+\frac{m h^{2}}{6}+2 m l^{2}+\frac{m_{o} R^{2}}{4}+\frac{m_{o} H^{2}}{12}$

Which is the inertia about $\mathrm{x}$-axis. By exactly similar procedure moment of inertia about $y-$ axis can be found.

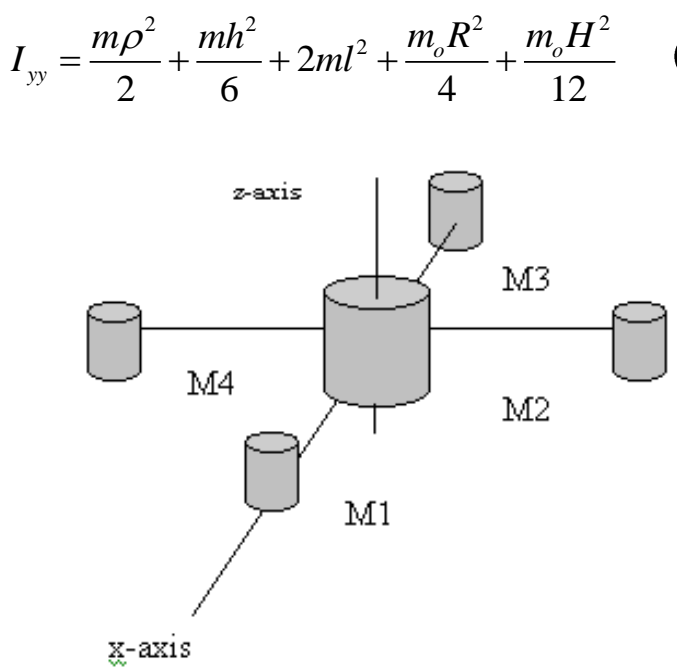

Fig.5. Moments of inertia about $x, y$ and $z$-axis.

\subsection{MOMENTS OF INERTIA ABOUT Z-AXIS}

Moment of inertia about z-axis, can also be calculated in two parts:

- Moment of inertia due to central hub.

- Moment of inertia due to motors $M_{1}$, $M_{3}, M_{2}$ and $M_{4}$.

For part (a) the moment of inertia due to central hub is: 
inertia $=\frac{m_{o} R^{2}}{2}$

For part (b) the moment of inertia due to motors $M_{1}, M_{3}, M_{2}$ and $M_{4}$ is:

inertia $=4 m l^{2}$

Therefore the total inertia about $\mathrm{z}$-axis is:

$$
I_{z z}=\frac{m_{o} R^{2}}{2}+4 m l^{2}
$$

\subsection{Products OF INERTIA}

Since the machine is assumed to be exactly symmetric products of inertia can be safely be neglected.

\section{THRUST AND VOLTAGE RELATIONSHIP}

The plant (quadrotor) input is voltage $\mathrm{Vi}$. And the propellers are generating thrust force, therefore a relationship between plant's input $\mathrm{Vi}$ and thrust force $\mathrm{Fi}$ is useful. This relationship is derived using momentum theory methodology.

The electrical power input into the motor as specified in [7] is :

$P=i V$

Suppose each motor's efficiency is $\eta$, then mechanical power output will be:

$P_{m}=\eta P=\eta i V$

Ideally the power induced in the air when the free stream air velocity is zero and the induced velocity is $v_{b}$, specified in [8] is:

$P_{h}=F v_{h}$

where $F$ is the thrust force of propeller. If $f$ is the figure of merit of propeller then mechanical power and the power induced in air can be related by:

$$
\begin{gathered}
P_{h}=f P_{m}=f \eta P=f \eta i V \\
P_{h}=f \eta i V
\end{gathered}
$$

A simplified model of dc separately excited motor is shown in Figure 6, where the inductance has been neglected, as its small for dc motors [7]. The motor constants are $K_{q}$ and $K e$.

$\tau_{m}=K_{q} i, e_{m}=K_{e} \Omega$

In (7.4) substituting (7.5) gives:

$P_{h}=f \eta\left(\frac{\tau_{m}}{K_{q}}\right) V$

The induced velocity $v_{h}$ is related to thrust, geometry of propeller and air density $\rho_{a}$ as mentioned in [9] by:

$v_{h}=\sqrt{\frac{F}{2 \rho_{a} A}}$

Therefore induce power in air is:

$P_{h}=F \sqrt{\frac{F}{2 \rho_{a} A}}$

The torque of propeller is proportional to the thrust generated by propeller [8] and constant of proportionality is $K_{t}$, therefore:

$\tau_{m}=K_{t} F$

Comparing (7.8), (7.6) and using (7.9) a relationship between thrust and voltage input to plant is obtained which is given bellow.

$F=2 \rho_{a} A\left[\frac{f \eta K_{t}}{K_{q}}\right]^{2} V^{2}$

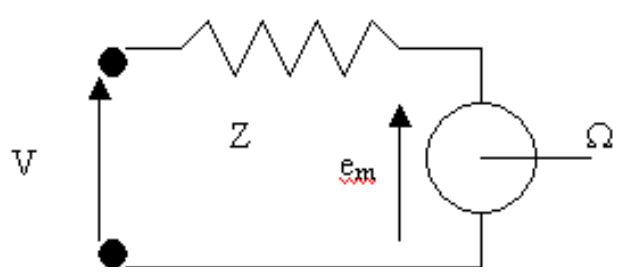

Fig.6. Simplified model of dc motor.

\section{ANGULAR VELOCITY OF PROPELLER AND VOLTAGE RELATIONSHIP}

In order to relate the plant output to the plant input a sub-system is formed. This sub-system relates the plant input to the motors speed, $\Omega$. The motor torque is given as:

$\tau_{m}=\tau_{d}+J \dot{\Omega}$

Using the $\mathrm{dc}$ motor model as specified in Figure 6 , motor input voltage is:

$V=e_{m}-i Z$ 
Using (7.5) and (8.1) in (8.3) voltage input to subsystem is given by:

$$
V=\tau \frac{Z}{K_{q}}+\frac{Z J \dot{\Omega}}{K_{q}}+K_{e} \Omega
$$

As specified in assumptions,

$$
\tau_{d}=D \Omega^{2}
$$

Using (8.3) and (8.4) a relationship between sub-system input and output is obtained:

$$
\frac{J Z \dot{\Omega}}{K_{q}}+K_{e} \Omega+\frac{Z D \Omega^{2}}{K_{q}}=V
$$

\section{DYNAMICS OF QUADROTOR}

Under the gravity and actuator action and no other external effects the machine experiences following motions:

1. Rolling about $\mathrm{x}$-axis

2. Pitching about $y$-axis

3. Yaw motion about z-axis
a. Vertical acceleration
b. Horizontal Acceleration

Since the focus here is on the hover control of quadrotor, and the fact that horizontal motion is a consequence of rotational motion [10], therefore relations for (1) to (4) are developed.

\subsection{ROLLING MOTION ABOUT X-AXIS}

As specified earlier, rolling motion is about $\mathrm{x}-$ axis. Rolling angular displacement as measured with respect to E-frame using right hand rule is $\Theta$. Therefore $\ddot{\Theta}$ expresses angular acceleration about $\mathrm{x}$-axis. And as found earlier moment of inertia of machine about $\mathrm{x}$-axis is $\mathrm{I}_{\mathrm{xx}}$. Therefore the rolling torque on machine is:

$$
\tau_{x x}=I_{x x} \ddot{\Theta} \hat{i}
$$

Here $\hat{i}$ is the unit vector in direction of $\mathrm{x}$-axis. The rolling torque is due to the thrust difference of motors $M_{2}$ and $M_{4}$. Due to the design of machine, the thrust force of each motor is assumed to be perpendicular to the plane of propeller and therefore the plane of quadrotor frame. As specified in section 3, the length of moment arm is $l$. Therefore the rolling torque is:

$$
\begin{aligned}
& I_{x x} \ddot{\Theta} \hat{i}=l \hat{j} x F_{2} \hat{k}+(-l \hat{j}) x F_{2} \hat{k} \\
& \text { or } \\
& I_{x x} \ddot{\Theta} \hat{i}=l\left(F_{2}-F_{4}\right) \hat{i}
\end{aligned}
$$

Here $I_{x x}$ is as in (6.4) and unit vector $\hat{i}$ specifies the direction of torque. Dropping the unit vector gives a simpler relationship.

$I_{x x} \ddot{\Theta}=l\left(F_{2}-F_{4}\right)$

Using (7.10) final equation for rolling motion is obtained as:

$\ddot{\Theta}=\frac{2 l \rho_{a} A}{I_{x x}}\left(\frac{f \eta K_{t}}{K_{q}}\right)^{2}\left[V_{2}^{2}-V_{4}^{2}\right]$

\subsection{PITCHING MOTION ABoUt Y-AXIS}

By repeating the derivation of previous section and using (6.5), with thrust forces of motors $M_{1}$ and $M_{3}$ relationship for pitching torque is obtained.

$I_{y y} \ddot{\Phi} \hat{j}=l\left(F_{3}-F_{1}\right) \hat{j}$

Here the unit vector specifies the direction of torque about y-axis. It can be dropped to simplify the relationship.

$I_{y y} \ddot{\Phi}=l\left(F_{3}-F_{1}\right)$

Using (7.10) final equation for pitching motion is obtained as:

$\ddot{\Phi}=\frac{2 l \rho_{a} A}{I_{y y}}\left(\frac{f \eta K_{t}}{K_{q}}\right)^{2}\left[V_{3}^{2}-V_{1}^{2}\right]$

\subsection{YAW MOTION ABOUT Z-AXIS}

Yaw motion is due to torque imbalance. As a propeller spins under machine torque it experiences a drag torque. This torque is exerted back on the machine as reaction torque and tends to spin the motor back. But since all the motors are connected to the frame of the machine, a net torque about $\mathrm{z}$ axis is experienced. This torque is responsible for yaw motion in accordance with right hand rule. 
Each motor supplies machine torque $\tau_{\mathrm{m}}$, which is balanced by the drag torque so the net torque on propeller, is:

$$
J \dot{\Omega}=\tau_{m}-\tau_{d}
$$

$J$ is the rotational inertia of the rotor and propeller of motor. If all the clockwise and counter clockwise torques are added, sum of torques is given by:

$\sum \tau=\tau_{m 2}+\tau_{m 4}-\tau_{m 1}-\tau_{m 3}$

The yaw torque is along z-axis given by:

$\tau_{z z}=I_{z z} \ddot{\Psi}$

In (9.10) the sum of machine torques is specified and reaction to these torques is in opposite direction to it. Therefore yaw torque is:

$$
I_{z z} \ddot{\Psi} \hat{k}=-\sum \tau_{z z} \hat{k}
$$

Unit vector specifies the direction of yaw torque. Dropping the unit vector for simplification, yaw torque is given by:

$$
I_{z z} \ddot{\Psi}=\tau_{m 1}+\tau_{m 3}-\tau_{m 2}-\tau_{m 4}
$$

Substituting (9.9) in (9.13) following equation is obtained:

$$
I_{z z} \ddot{\Psi}=J\left(\dot{\Omega}_{1}+\dot{\Omega}_{3}-\dot{\Omega}_{2}-\dot{\Omega}_{4}\right)+\left(\tau_{d 1}+\tau_{d 3}-\tau_{d 2}-\tau_{d 4}\right)
$$

Using (8.4) final equation relating the output of sub-system to the plant out puts is obtained.

$$
I_{z z} \ddot{\Psi}=J\left(\dot{\Omega}_{1}+\dot{\Omega}_{3}-\dot{\Omega}_{2}-\dot{\Omega}_{4}\right)+D\left(\Omega_{1}^{2}+\Omega_{3}^{2}-\Omega_{2}^{2}-\Omega_{4}^{2}\right)
$$

\subsection{VERTICAL ACCELERATION}

The four spin propeller, two clockwise and two counterclockwise, generate thrust force that is perpendicular to the plane of propellers. Therefore when roll and pitch angle is zero it is along z-axis. But when roll or pitch angle is not zero then a component of this force $F_{\text {total }} \cos \Theta \cos \Phi$ acts along the zaxis. Weight of the machine always acts along negative z-axis therefore this component of thrust force has to cancel it out in order to lift the machine in air.
The net force acting at the center of mass of machine is :

$$
F_{n e t}=M a_{z}=\left(F_{1}+F_{2}+F_{3}+F_{4}\right) \cos \Theta \cos \Phi-M g
$$

Here $M$ is the net mass of the machine. Using (7.10), a relationship between vertical acceleration and voltage input to system can be deduced.

$$
a_{z}=\frac{2 \rho_{a} A}{M}\left(\frac{f \eta K_{t}}{K_{q}}\right)^{2}\left(V_{1}^{2}+V_{2}^{2}+V_{3}^{2}+V_{4}^{2}\right) \cos \Theta \cos \Phi-g
$$

Equations (9.17), (9.8) and (9.5) relate the system inputs $V_{i}$ to system outputs, roll, pitch and vertical acceleration. Equation (8.5) constitutes a sub-system which relates the system input $V_{i}$ to the motor output $\Omega_{\mathrm{i}}$. proposed mathematical model of the dynamics of quadrotor helicopter. Equation (9.15) relates the sub-system outputs the motor speeds to the system output yaw angle. All these equations describe the dynamics of quadrotor helicopter.

\section{NEURAL NETWORKS FOR CONTROL}

In its essence, to control a system, is to force the system to behave in a desired way. The desired behavior is determined by the task to be solved but the dynamics of the system, the limitation of actuators and the available computational power etc. influence this desired behavior in many ways. Fundamentally there are two problems that need to be addressed, namely:

i) Regulation Problem: here the task of controller is to keep the output of the system at constant level regardless of disturbances etc.

ii) Servo Problem: here the task of controller is to make the system follow a reference trajectory. 
Neural networks have been exploited to control the dynamic systems using a number of different methodologies, for instance Model Reference Adaptive Control ([11] and [12]), Direct Inverse Control etc. Direct inverse control is considered in the paper.

\subsection{BASICS OF NEURAL NETWORKS}

Neural Network is a relatively new discipline; therefore the mathematical notations and architectural representations for "neural networks" have not yet been self-assuredly recognized. The publications on neural networks have come from researchers working in many diverse disciplines, such as psychology, mathematics, engineering physics etc. Moreover most of the researchers use vocabulary typical to their domain. Consequently, most of the literature in this field is not easy to interpret, and ideas are apparently more convoluted than they are in reality. This has often resulted in branded concepts being rediscovered, therefore in this text in order to avoid any ambiguity, we will adhere to the notations and architectural representations as adopted in [12].

In 80 s, the field of neural networks received renewed interest. Of many reasons one of the reason for the refreshed interest in neural networks was the paper by Rumelhart which made the backpropagation algorithm famous [13]. The algorithm had actually been invented and reinvented many times before, as early as in 70 s. But only in 80 s did the algorithm receive the attention it deserved. This happened because of the advancement in computing technology.

\subsection{The Perceptron and Mulitple Layer PERCEPTRON}

A single layer neural network with weighted inputs and biases is called a perceptron. The network can be trained by some algorithm. Training simple means finding appropriate values of biases and weights so as to have the network produce desirable output. A simple perceptron trained by a simple training algorithm, can be used to solve a simple classification problem. But perceptron has a limitation, it can only solve linearly separable problems. A linearly separable problem can simply be one where data points can be separated by a straight line (in 2D).

The network shown in figure 7 is known as a "Multiple Layer Perceptron" in literature. Multiple layer perceptrons have at least one hidden layer and an output layer. There can be more than one hidden layers but for most of the control system applications one hidden layer is sufficient [13] Finding the appropriate weights and biases is achieved through a process called training or learning, which can be done by executing an algorithm such as back-propagation [14].

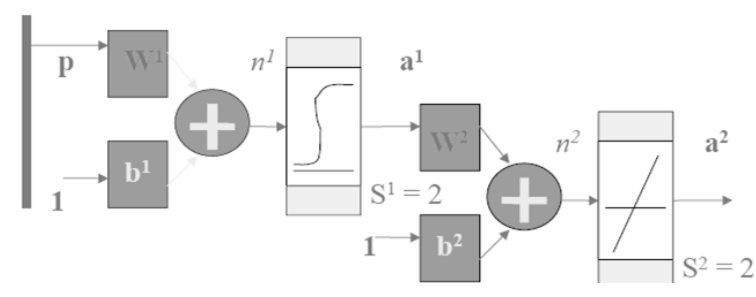

Fig.7. Multiple Layer Perceptron

Multiple Layer Perceptrons can solve the problem of linearly inseparability [12]. In figure 7, a Multiple Layer Perceptron with layer one as log-sigmoid and linear second layer, is shown. A multiple layer perceptron shown above can solve any function approximation problem provided sufficient number of neurons and layers are there. Cybenko's theorem states that, "A feedforward neural network with a sufficiently large number of hidden neurons with continuous and differentiable transfer functions can approximate any continuous function over a closed interval" [15]. Such a network was proposed as early as 1960 s but 
lost all interest because technology was not available to use it. However in 1980 David Rumelhart reinvented an algorithm known as "Backpropogation" to train a multi-layer perceptron given that we have a training set of data (inputs and corresponding outputs). Backpropagation Algorithm is a steepest decent algorithm, where the square of error between target output and actual output is minimized.

As mentioned earlier multi-layer perceptrons require training to perform required function. For that matter some training algorithm is mandatory. The most powerful of such algorithm is "Backpropagation Algorithm".

\subsection{Network Training AND Back- PROPAGATION}

The neural network explained in the previous section were invented in 1960 s, but they lost all research interest because of unavailability of appropriate algorithm or inability of its implementation so as to find appropriate weights. However in 1980 a researcher, David Rumelhart, invented an algorithm known as "Back-propagation" to train a multiplayer perceptron provided a training set of data (inputs and corresponding outputs) is available.

Back-propagation is steepest decent algorithm that minimizes the square of error between the target value and the actual output. The term back-propagation refers to the fact the error is propagated backward from out to the input. This is done in two steps; firstly the inputs are propagated forward from all the layers till the final output. This output is then compared with the target output. The error or the difference between the two sets of output is then propagated backward and sensitivities at the input of every layer's activation function are evaluated. These sensitivities are then used to calculate new weight and bias values. Equation (10.1) is used to execute the first step (see [12] for details).

$$
\begin{gathered}
a^{0}=p \\
a^{m+1}=f^{m+1}\left(W^{m+1} a^{m+1+b^{m+1}}\right)
\end{gathered}
$$

here $\mathrm{m}=0,1,2 \ldots$ layer number.

$$
\begin{aligned}
s^{M} & =-2 F^{\prime} M(n M)(t-a) \\
s^{m} & =F^{\prime} m(n m)(W m+1) s^{m+1}
\end{aligned}
$$

here $m=M-1, \ldots, 2,1$

Finally the weights are updated using:

$$
\begin{aligned}
& W^{m}(k+1)=W^{m}(k)-a s^{m}\left(a^{m-1}\right)^{T} \\
& b^{m}(k+1)=b^{m}(k)-a s^{m}
\end{aligned}
$$

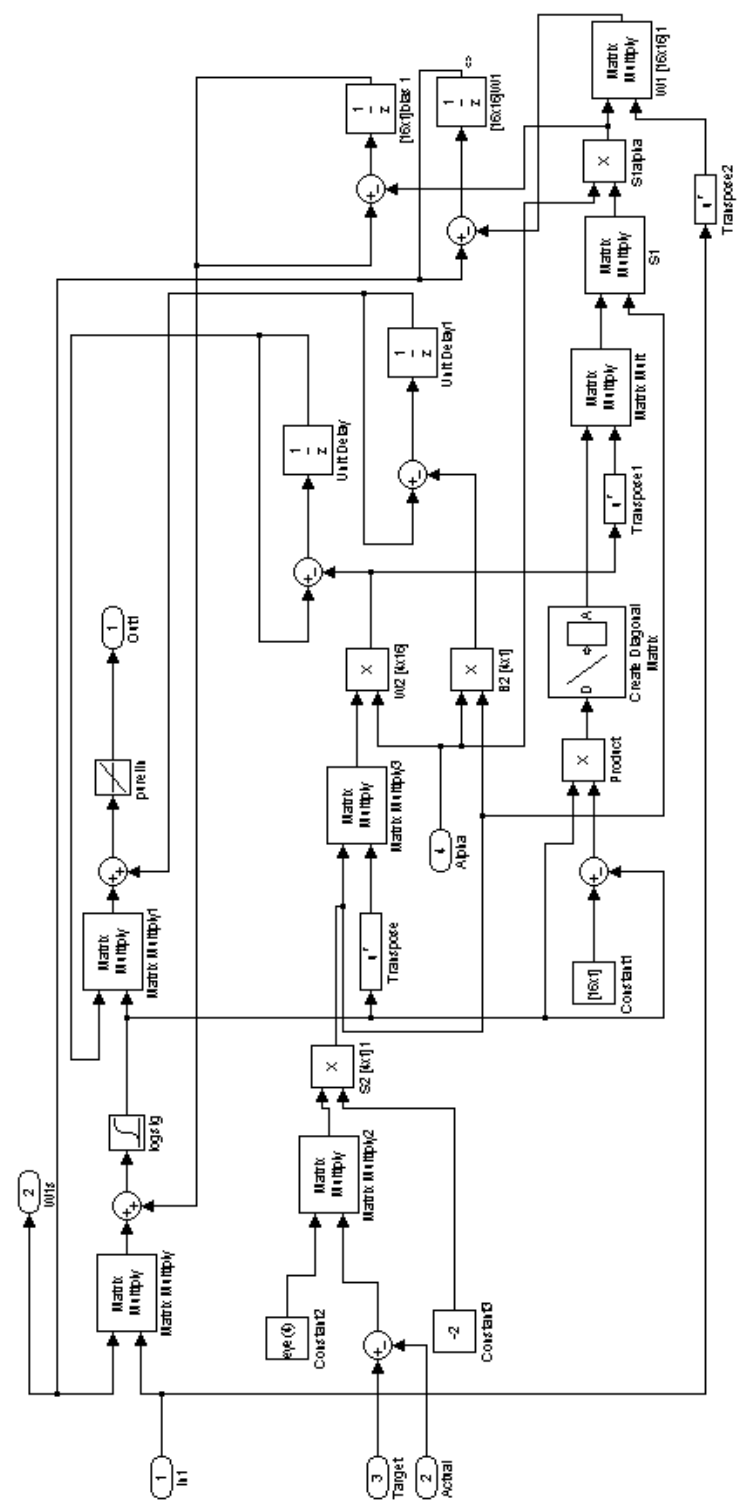

Fig.8. MLP with Back Prop Algorithm 
In (3), $F^{\prime}$ is defined as:

$$
\mathrm{F}^{\prime} \mathrm{m}(\mathrm{nm})=\left(\begin{array}{cccc}
f^{\prime} m\left(n_{1} m\right) & 0 & 0 & 0 \\
0 & f^{\prime} m\left(n_{2} m\right) & 0 & 0 \\
0 & 0 & f^{\prime} m\left(n_{3} m\right) & 0 \\
0 & 0 & 0 & f^{\prime} m\left(n_{4} m\right)
\end{array}\right)
$$

Where,

$$
\left.f^{\prime} m_{\left(n_{j}\right.} m\right)=d f^{m}\left(n_{j} m\right) / d\left(n_{j} m\right)
$$

Where $f$ is activation function of $j$ th neuron in $m$ th layer and $n$ is net input function. In this work the above explained back propagation algorithm is implemented in form of Simulink ${ }^{\oplus}$ Model. It can also be automated in form of a Matlab ${ }^{\oplus}$ code. Figure 8 shows the Simulink model of neural network with embedded back propagation algorithm as explained above.

\section{DIRECT-INVERSE CONTROL}

Direct-Inverse control scheme originates from the very early phase of neural networks development, when an idea was proposed to control non-linear plant by training a neural network to act as an inverse of plant to cancel out its dynamics [4]. This is the basic idea behind the direct inverse control where the network acts as inverse of plant so as to cancel out the plant dynamics and the desired response is thus obtained [8]. Neural networks have been used successfully to control dynamic systems [6]. The generalized architecture for Direct-Inverse control is given in Figure 5. The controller is trained as inverse of the plant model. For that reason the error between controller output and inverse of plant model must minimized. Therefore the inverse of plant model is also required to be found.

The mathematical model of the quadrotor has already been found. In order to apply direct inverse neural control, we need to have simulation model. That simulation model is developed next.

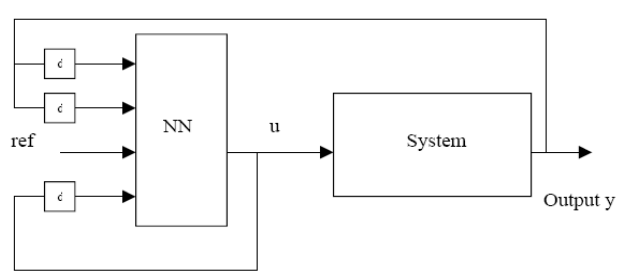

Figure 9. Direct Inverse Control

\subsection{SimUlinK@ MODEL OF QUADROTOR}

Equation (8.5) relates the angular velocity and voltage input of motor. Figure 10.a shows a Simulink ${ }^{\otimes}$ Model implementing this equation. It is non-linear model based on second order non-linear equation. Next is the sub-block that relates the voltage inputs to the roll and pitch angular accelerations. This sub-block is based on (9.5) and (9.8) and shown in figure 10.b. Figure 11, shows the vertical acceleration sub-block, which is based on (9.17).

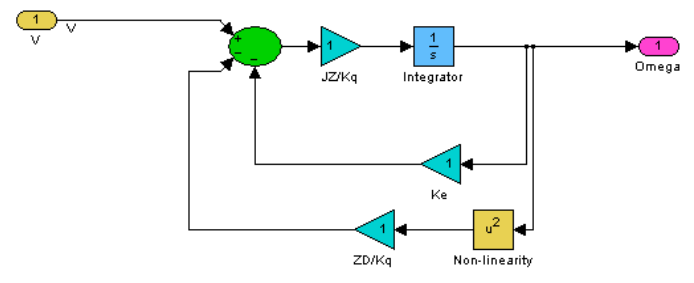

(a)

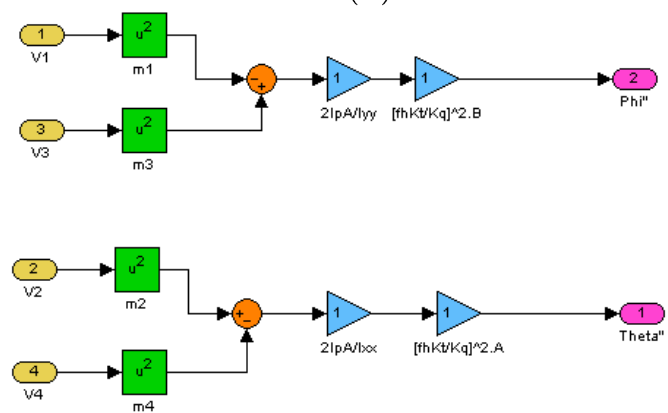

(b)

Fig.10. a) Voltage to Velocity Sub-Block, b) Roll, Pitch Sub-Block

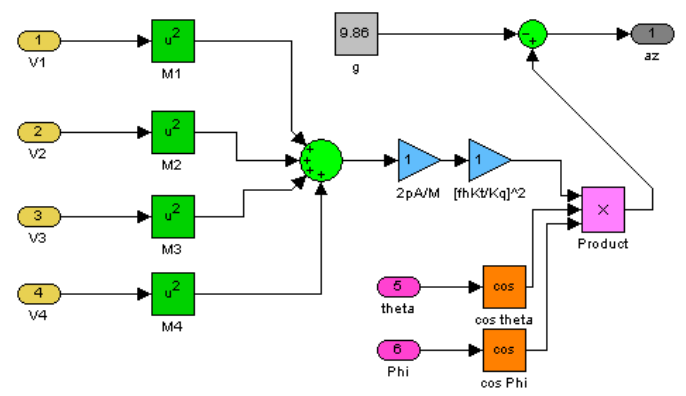

Fig.11. Vertical Acceleration Sub-Block 


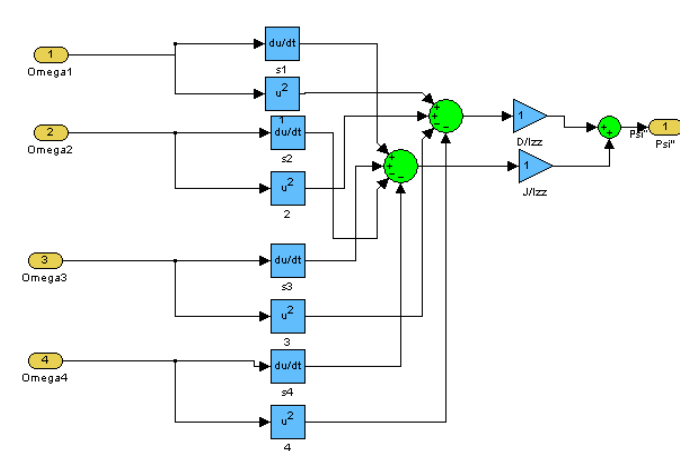

Fig.12. Quadrotor Plant Model.

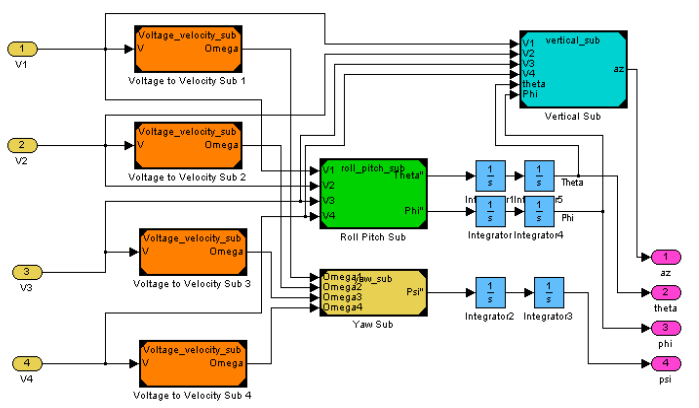

Fig.13. Quadrotor Plant Model.

Finally a sub-block relating the yaw angular displacement and the speeds of propellers is depicted in figure 12. this sub-block is based on (9.15). All these sub-blocks shown in previous figures are collected together in block shown in figure 13.

\subsection{Calibration of Quadrotor Plant Model}

The Simulink ${ }^{\oplus}$ model developed so far is an un-calibrated model. For calibration we need to have a set of realistic values of various parameters taken from practical system. Table 1 shows the list of various quantities used in calibration of model. These quantities have been taken form OS4 Project [16] (Courtesy of Sameer $e t a l$.).

\subsection{InVERSE OF QUADrotor Plant AND ITS SIMULINK® MODEL}

In order to find out the inverse model of quadrotor plant the method adopted is, first linearize the quadrotor dynamics and then find the inverse of the Laplace Transform of linearized model. Then the Simulink ${ }^{\otimes}$ model can be easily developed.
By using first order Taylor Series and set the operating point as the however state, where the roll, pitch and yaw angular displacements and vertical acceleration are zero, the mathematical model developed in the first part of the paper is linearized. The linearized model is given in following equation.

$\frac{d}{d t}(\Delta \Omega)=\left(\frac{-Q-S \Omega_{Q}}{P}\right) \Delta \Omega+\frac{1}{P} \Delta V$

$\frac{d}{d t}(\Delta \dot{\Theta})=2 M V_{Q}\left(\Delta V_{2}-\Delta V_{4}\right)$

$\frac{d}{d t}(\Delta \dot{\Phi})=2 M V_{Q}\left(\Delta V_{3}-\Delta V_{1}\right)$

$a_{z}=2 X V_{Q}\left[\Delta V_{1}+\Delta V_{2}+\Delta V_{3}+\Delta V_{4}\right]$

The Laplace Transform of the transfer function of the linearized model can be very easily found. And by using MATLAB ${ }^{\circledR}$ commands $\operatorname{inv}($.$) the inverse model can be$ found.

TABLE 1: CALIBRATION DATA FOR THE QUADROTOR.

\begin{tabular}{|c|c|c|c|c|}
\hline & Parameter Name & Symbol & $\begin{array}{c}\text { Numerical } \\
\text { Value }\end{array}$ & Unit \\
\hline 1 & $\begin{array}{l}\text { Rotational Inertia } \\
\text { alon } x \text {-axis, } y \text {-axis }\end{array}$ & Ixx, Iyy & 0.0075 & $\mathrm{~kg} \cdot \mathrm{m}^{2}$ \\
\hline 3 & $\begin{array}{l}\text { Rotational Inertia } \\
\text { alon z-axis }\end{array}$ & Izz & 0.0013 & $\mathrm{~kg} \cdot \mathrm{m}^{2}$ \\
\hline 4 & Total Mass & $\mathrm{M}$ & 0.65 & $\mathrm{~kg}$ \\
\hline 6 & Drag Constant & $\mathrm{D}$ & $7.50 \mathrm{E}-07$ & N.s ${ }^{2}$ \\
\hline 7 & Prop Radius & $\mathrm{Rp}$ & 0.15 & $\mathrm{~m}$ \\
\hline 8 & Prop Disc Area & $\mathrm{A}$ & 0.07069 & $\mathrm{~m}^{2}$ \\
\hline 12 & Rotor Inertia & $\mathrm{Jr}$ & $6.04 \mathrm{E}-05$ & kg. $\mathrm{m}^{2}$ \\
\hline 13 & Arm Length & 1 & 0.23 & $\mathrm{~m}$ \\
\hline 14 & Motor wieght & $\mathrm{m}$ & 51 & $\mathrm{~g}$ \\
\hline 15 & $\begin{array}{l}\text { Motor dc } \\
\text { Resistance }\end{array}$ & Z & 0.6 & Ohms \\
\hline 16 & $\begin{array}{l}\text { Motor Torque } \\
\text { Constant }\end{array}$ & $\mathrm{Kq}$ & 0.0018 & $\mathrm{Nm} / \mathrm{A}$ \\
\hline 17 & $\begin{array}{l}\text { Motor Speed } \\
\text { Constant } \\
\end{array}$ & $\mathrm{Ke}$ & 0.0015 & V.s/rad \\
\hline 18 & Motor efficiency & eta & 64 & $\%$ \\
\hline 19 & Air Density & $\mathrm{pa}$ & 1.1 & $\mathrm{~kg} / \mathrm{m}^{3}$ \\
\hline 20 & Figure of Merit & $\mathrm{f}$ & 0.5 & NIL \\
\hline 21 & $\begin{array}{l}\text { Thrust/Torque } \\
\text { Constant }\end{array}$ & $\mathrm{Kt}$ & 0.00056 & $\mathrm{~m}$ \\
\hline
\end{tabular}

The transfer function matrix of the inverse of the plant is given next. 
$\operatorname{Ginv}=\left[\begin{array}{c}0,-500 / 3047^{\star} s^{2}, 1 / 6^{\star} s^{\wedge} 2 /\left(31^{*} s+274\right)^{*}\left(1000^{*} s+87\right), 250 / 153 \\ 0,-500 / 3047^{*} s^{2}, 1 / 6^{*} s^{\wedge} 2 /\left(31^{*} s+274\right)^{*}\left(1000^{*} s+87\right), 250 / 153 \\ 0,-500 / 3047^{*} s^{2}, 1 / 6^{*} s^{\wedge} 2 /\left(31^{*} s+274\right)^{*}\left(1000^{*} s+87\right), 250 / 153 \\ 0,-500 / 3047^{*} s^{2}, 1 / 6^{*} s^{\wedge} 2 /\left(31^{*} s+274\right)^{*}\left(1000^{*} s+87\right), 250 / 153\end{array}\right]$

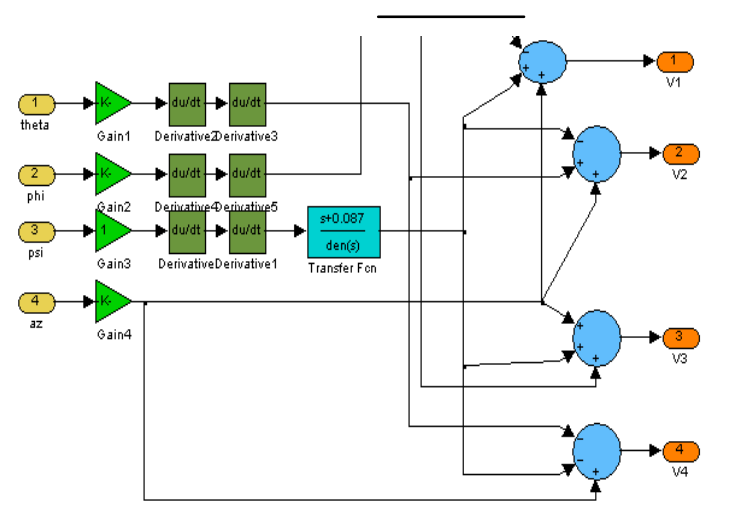

Fig. 14. Inverse of Quadrotor.

Based on the transfer matrix given above a Simulink ${ }^{\circledR}$ Model of the inverse of the Quadrotot is developed. This Model is shown in figure 14.

\subsection{DiRECT INVERSE CONTROL OF QUADROTOR}

The basic idea of direct inverse control is to train a neural network as an inverse of given plant and apply its output directly to plant, so as to cancel out the dynamics of the plant and make the response to follow the reference signal. The neural network takes as input the reference signal, the output of the plant passed through tapped delay line and the delayed output of the network itself.

In the direct inverse control of quadrotor plant, the error is between the network outputs, which is also the control signal, and the target control signal that should be there for making the plant follow the reference trajectory. In this case this target control signal has been obtained form the output of inverse of linearized plant model at operating point developed in the last chapter. Figure 15 shows the Direct Inverse Control of Quadrotor.
The detailed Simulink ${ }^{\circledR}$ Model of the complete system, is shown in figure 15 . There are four reference signals namely the roll, pitch and yaw angles and vertical acceleration. In this model these signals are sinusoids of low frequencies $(0.001 \mathrm{rad} / \mathrm{sec})$. The amplitude is kept close to zero $(=0.01)$ since this is the desired response the plant should exhibit. These reference signals are fed to the inverse model. The controller is a multiple layer perceptron All the signals fed to the network are passed through sample and hold running at $100 \mathrm{~Hz}$.

The neural network shown in the figure by a "yellow" colored block, receives the reference inputs, the output of the plant passed through tapped delay lines having two delays for each signal, the output of the network passed through delays These delays are shown in the block diagram by small "pink" colored blocks.

The neural network also has other inputs which are labeled as the target value and the actual output. The target input receives the inputs from the output of the inverse plant model. And the actual receives the output of the network itself.

The controller generates four control signals V1 to V4, which are the motor speed control inputs of the plant. During the initial 18 seconds of the first plant operation, set rather arbitrarily on the basis of system performance, the plant is not controlled by the controller but instead receives a constant input. During this time the controller is trained to generate a control signal that makes the plant to respond the way it would respond to a constant operating input (this mode of operation corresponds to the tuning of conventional controller). Once the controller has been trained it starts its operation and takes over control of the machine. The training is not stopped and it continues. This makes the 
algorithm adaptive in a way that the weights get updated during the normal operation and any perturbation in any plant parameter can be defied.

In short the operation of system can be explained as; the controller compares the plant response with the reference input and generates a control signal in accordance with the control signal generated by the inverse plant model for that particular reference signal and hence the plant outputs are regulated to maintain hover-state.

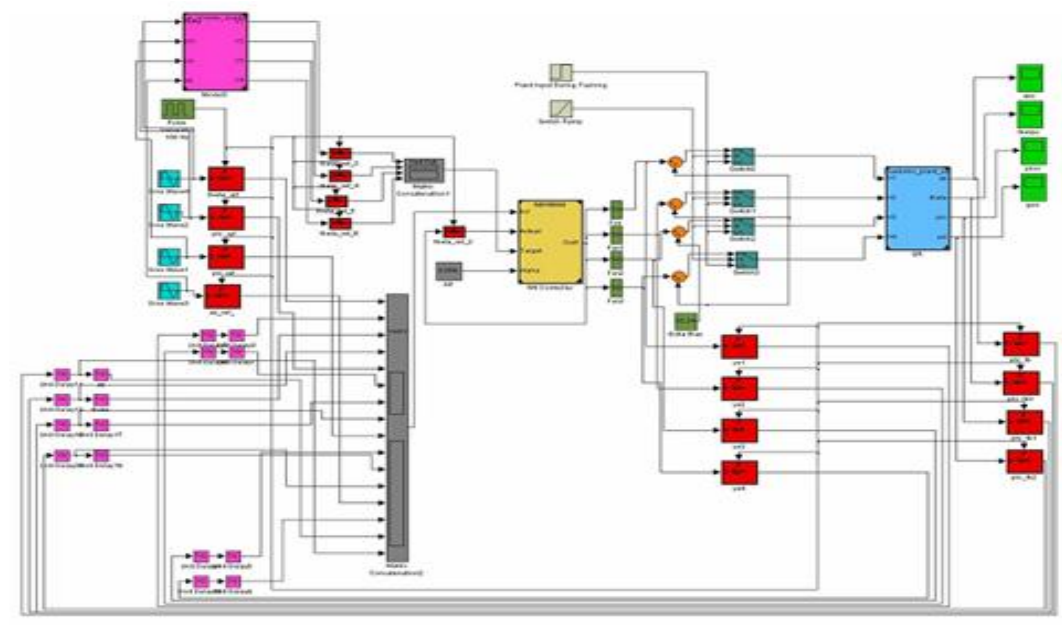

Fig.15. Direct Inverse Control of Quadrotor.

\subsection{SIMULATION AND RESULTS}

Figure 16 shows the response of the plant when a 16,64,4-MLP was used. The figure shows the quadrotor is in hover state where the roll and pitch angles are at zero. There is an initial transition in the vertical acceleration, the vertical acceleration increases from $-3.0 \mathrm{~m} / \mathrm{s}$ to 0 , corresponding to hover condition. However the graph shows over shoot of $3.1 \mathrm{~m} / \mathrm{sec}$ and damped oscillations with settling time of $3.9 \mathrm{sec}$. the rise time is 6 sec. The yaw, pitch and roll angular displacements are all zero. Therefore it can be safely stated that the dynamics of quadrotor have been controlled at hover state.

\section{CONCLUSION}

The control algorithm for In-Flight control the quadrotor helicopter proposed in this paper demonstrates the application of neural networks for the control of nonlinear dynamic systems. Briefly summarizing the control algorithm, it can be said that the neural network generates the control signal to control the quadrotor plant with respect to the output of linearized model of inverse of plant, so as to make the plant follow the reference input. The result is a system that is stabilized in the hover state.

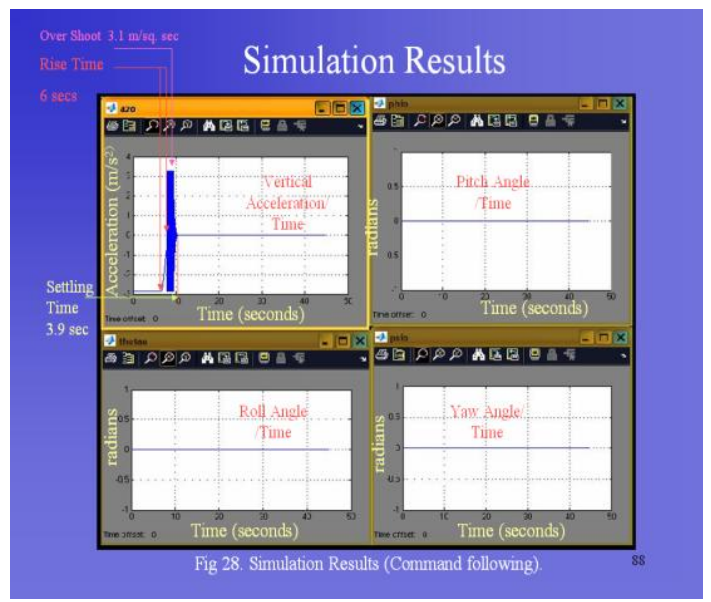

Fig.16. Response of controlled system.

\section{ACKNOWLEDGEMENT}

The authors would like to thank all the brilliant minds whose guidance has been extremely fruitful. 


\section{REFERENCES}

[1] Arda Özgur Kivrak, "Design of Control Systems for a Quadrotor Flight Vehicle equipped with inertial Sensors", Masters Thesis Atilim University Turkey, 2006, pp. 4-29.

[2] Ponds P., Mahony R., Gresham J., Corke P. and Roberts J., "Towards Dynamically Favourable Quad-Rotor Aerial Robots", In Proc. of Australasian Conference on Robotics and Automation, Canberra, Australia, 2004.

[3] Prinz I., "The Mesicopter: A Meso-Scale Flight vehicle", http://aero.stanford.edu/mesicopter/.

[4] BouabdAllah S., Murrieri P., Siegwart R., "Towards Autonomous Indoor Micro VTOL", Autonomous Robots 18, Springer Inc, 2005, pp. 171-183.

[5] Ponds P., Mahony R and Corke P., "Modeling and Control of Quad-Rotor Robot", In Proc. of Australasian Conference on Robotics and Automation, Sydney, Australia, 2005.

[6] Resnick R., Halliday D., Krane K., Physics, Vol. 1 $4^{\text {th }}$ Edition, John Wiley and Sons, Inc, pp. 231-240.

[7] Goodwin G., Graebe S., Salgado M., Control Systems Design, Pearson Education, Inc. , pp. 41-65

[8] Hoffmann G. M., Huang H, Waslander S L., and Tomlin C J., "Quadrotor Helicopter Flight Dynamics and Control: Theory and Experimentation, AIAA Guidance", Navigation and Control Conference, 2007.

[9] Leishman, J.G, Principles of helicopter Aerodynamics, Cambridge University Press, NewYork NY, 2000.

[10] BouadAllah S., Noth A. and Siegwart R., "PID versus LQ Control Techniques Applied to an Indoor Micro Quadrotor", In Proc. of the IEEE International Conference on Intelligent Robots and Systems, Sendai, Japan, 2004.

[11] Norgaard M., Raven O., Poulsen N. K., L. Hansen K., "Neural Networks for Modelling and Control of Dynamic Systems", Springer-Verlag, 2000, pp. 121-178.

[12] Hagan M. T., Demuth H. B and Beale M, Neural Network design, Chapter No. 2, 3, 4 and 7 , Published by PWS, 1996.

[13] Raul Rojas, Neural Network a Systematic Introduction, Springer-Verlag, 1995, pp. 55-75.
[14] Simon Haykin, Neural Networks a Comprehensive Foundation, $2^{\text {nd }}$ edition, Published by Pearson Education Inc, 1999, pp. 32-40.

[15] Cybenko G., "Approximation by superposition of a Sigmoidal Function, Mathematics of Control, Signals and Systems", Vol. 2(4), 1989, pp. 303-314.

[16] Sameer BouabdAllah, "Design and Control of Quadrotors with Application to Autonomous Flying", Phd Thesis, Swiss Federal Institue of Technology, 2003. 


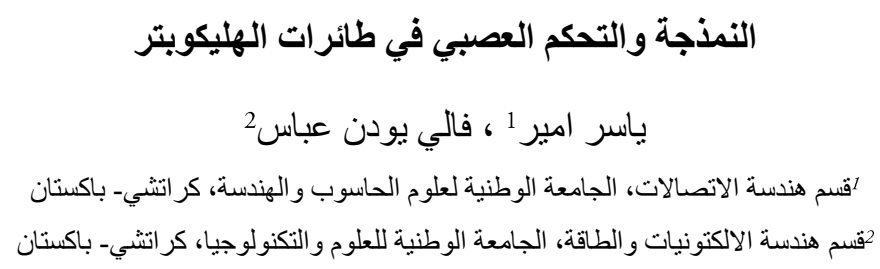

الملخص:

طائرة الهليكوبتر هي طائرة عمودية تمللك أربع مر اوح لتوليد قوة الرفع. تدور مروحتان مع عقارب الساعة بينما تدور المروحتان الاخريتان بعكس عقارب الساعة. يمكن التحكم بهذه الآلة بتغيير السرعة النسبية للمراوح. أن مبدأ طائرة الهيلكوبتر ليس جديدا، و على أية حال فان الطائر ات العمودية الحديثة غير مأهولة في معظم الأحيان. أن التقدم في تكنولوجيا (IMU) ونوفر محركات خالية من الفحمات وذات سرعة عالية و نسبة طاقة الى وزن عالية البطارية وتكنولوجيا بطاريات الليبولمر، كل ذلك ساهم في تحسين تصميم وتصنيع طائرات الهيلكوبتر. وتقترح هذه الورقة نموذجاً رياضياً لدر اسة ديناميكا وطريقة التحكم المبنية على أساس التحكم العصبي المباشر المعكوس. وقد تم اعتماد طريقة مبسطة بإهمال التأثير توازني واحتكاك الهو اء على هيكل الطائرة مما ساهم في إيجاد نموذج مبسط ومفيد في تصميم متحكم للاستقرار للطائرة وهي تحوم. أن النموذج المقترح هو غير خطي لان ديناميكا المروحة تعتمد على مربع مدخلات المحرك. تقوم وحدة التحكم المعتمدة على الثبكة العصبية و القائمة على بريكتون perceptron متعدد الطبقات يدار بخوارزمية الانتشار الخلفي. أن مخطط السيطرة المباثرة المعكوس بستخدم فكرة تقوم على إلغاء دينامياكيات الوحدة من خلال وحدة التحكم لتقريب معكوس للمحطة. ويتطلب هذا النظام أن يكون للمحطة معكوسا مستقرةً. 